\title{
ISOLAMENTO DE VIRUS DE COPOS DE BARES E CAFÉS DA CIDADE DE SÃO PAULO (1)
}

\author{
José Alberto N. CANDEIAS \\ Dacio de Almeida CHRISTOVÃO \\ Luis G. COTILLO Z.
}

\begin{abstract}
De $8,75 \%$ dos 80 lotes de copos, prontos para uso, de 40 «bares e cafés» do centro da cidade de Săo Paulo, foram isoladas 7 cêpas de virus, sendo três de adenovírus do tipo 3 , duas de virus ECHO 11, uma de adenovírus do tipo 4 e uma de virus do herpes simples. Cada lote era constituido de 5 copos. Os 7 lotes positivos provinham de $y$ ubares e cafés» diferentes. Estes achados comprovam a má situacão sanitária dos utensílios de uso comum nos estabelecimentos públicos de distribuição de alimentos e bebidas da cidade de São Paulo, já evidenciada através de investigações bacteriológicas anteriores, resultam da falta total de aplicação das medidas de saneamento de tal material, nesses locais. As condições existentes são conseqüência das disposições inoperantes e até impraticáveis da atual legislação sanitária estaduạl concernente à matéria.
\end{abstract}

I N T R O D U C A O

A possibilidade da transmissão, do portador a outro indivíduo, de microrganismos patogênicos - vírus, bactérias, cogumelos e protozoários - através de copos, xícaras e talheres de bares, cafés ou restaurantes, quando êstes utensílios não são adequadamente lavados e desinfectados, é reconhecida por todos aquêles a par da capacidade de resistência dêsses microrganismos no meio exterior.

Embora não haja conhecimento exato da importância epidemiológica dessa via de transmissão $\mathrm{e}$, provàvelmente, nem possa, nas condições naturais, ser obtido tal conhecimento, as autoridades sanitárias estão de acôrdo que não deve ser aceitável a falta de instituição, de regulamentação e de contrôle de medidas capazes de impedir a operação de tal via ou, pelo menos, de reduzí-la ao mínimo possível. Tendo em vista tais objetivos, os códigos sanitários dos diferentes paises preconizam medidas diversas, mais ou menos estritas $e$, às vêzes, totalmente inadequadas, a serem adotadas na lavagem e desinfecção de tais utensílios.

A Associação Americana de Saúde Pública ${ }^{1}$ (1944) propôs um método e um padrão bacteriológicos para o contrôle das condições de saneamento dêsses utensílios. Tal técnica e tal padrão passaram a ser adotados oficialmente nos Estados Unidos, bem como em outros países, como o Canadá e a União Sul Africana. A aplicação dêsse método em duas investigações, realizadas por Christovão 4, 5 (1947, 1956), veio revelar as péssimas condiçóes sanitárias dos utensílios de restaurantes, bares e cafés do centro da cidade de São Paulo, através dos elevados números de bactérias presentes na grande maioria dos utensílios examinados e até mesmo da demons-

Recebido para publicação em 30-8-1968.

(1) Da Cadeira de Microbiologia Aplicada da Faculdade de Higiene e Saúde Pública da USP. 
CANDEIAS, J. A. N.; ChRIStOvaO, D. de A. \& COTILLO Z., L. G. - Isolamento de virus de copos de bares e cafés da cidade de.. Rev. Saúde públ., S. Paulo, 2(2):174-179, dez. 1968.

iração da existência de bactérias patogênicas em elevada proporção dos mesmos.

Parecendo continuar a existir em São Paulo, hoje em dia, a mesma situação de 1947 e 1956, julgaram os autores que o isolamento de vírus, a partir dos utensilios dados como lavados e prontos para uso, de bares e cafés ou restaurantes do centro da cidade, deveria ser perfeitamente possível e bastante provável, embora $o$ isolamento de vírus de material desta natureza ainda não tenha sido relatado por nenhum investigador. Baseados nesta presunção, levaram a efeito a presente investigação.

\section{MATERIAL E M TODOS}

Area de estudo e amostragem - Delimitou-se uma área central (1) da cidade e dentro dela escolheram-se as ruas ou largos e praças principais. Estabeleceu-se, em seguida, um itinerário ao longo dos limites e das ruas, largos e praças escolhidos e se decidiu que cada quinto "bar e café" encontrado ao longo dêste itinerário, assim prefixado, até se atingir o total de 40 estabelecimentos, teria seus utensílios examinados. No caso de recusa no fornecimento do material para exame, seria tomado o estabelecimento seguinte e a contagem reiniciada a partir dêste.

Material - De cada um dos 40 "bares e cafés" foi colhido material de 2 lotes de copos já lavados, prontos para uso, de 5 copos cada um. Foram examinados, assim, 80 lotes, correspondentes ao total de 400 copos.

Examinaram-se ùnicamente copos, baseando-se nos dados dos dois inquéritos anteriores (CHRISTOVÃo ${ }^{4,5}$ 1947, 1956) que revelaram serem êstes os utensilios em pior condição sanitária. Não tendo ha- vido, em São Paulo, nenhuma modificação no sistema de lavagem e desinfecção dos utensílios, não havia nenhuma razão para que não continuassem a ser êstes os utensílios com maior número de bactérias e, presumìvelmente, aquêles que maiores probabilidades apresentariam de estarem mais contaminados com vírus.

A colheita de material de cada lote de copos foi realizada de acôrdo com a técnica padrão da Associação Americana de Saúde Pública ${ }^{1}$ (1944), apenas substituindo-se a solução salina tamponada padrão - destinada a molhar os "swabs" de colheita de material e a servir de meio de transporte - por solução salina de Hanks, adicionada de $0,5 \%$ de gelatina, $200 \mathrm{u} /$ $/ \mathrm{ml}$ de penicilina e $200 \mathrm{u} / \mathrm{ml}$ de estreptomicina. Os chumaços de algodão foram sempre montados em arame de alumínio.

0 material colhido era transportado ao laboratório, dentro das condições impostas pela técnica padrão (APHA ${ }^{1}, 1944$ ). Depois da agitação requerida, os chumaços de algodão, após serem espremidos com pinças estéreis, eram desprezados e o material foi sempre imediatamente congelado a $-20^{\circ} \mathrm{C}$, condição na qual permaneceu até a sua inoculação para a pesquisa da eventual presença de vírus.

Tempo de estudo - A presente investigação foi empreendida em duas épocas. 0 material dos primeiros 20 "bares e cafés" foi colhido nos dias 15 e 16 de agôsto e 5 e 6 de setembro de 1967 e dos segundos 20 "bares e cafés", nos dias 23 e 24 de janeiro e 20 e 21 de fevereiro de 1968. Assim, a primeira época corresponde à segunda metade do inverno e a segunda, aos 30 dias do meio do verão.

A colheita foi realizada sempre entre as 15:00 e 16:00 horas.

(1) Os limites de área estudada são: Av. Ipiranga (a partir da esquina da Av. São Luiz), Av. Cásper Líbero, Largo Santa Ifigênia, Viaduto Santa Ifigênia, Largo São Bento, Rua Boa Vista, Páteo do Colégio, Praça da Sé, Rua Santa Tereza, Praça Clóvis Bevilacqua, Rua Anita Garibaldi, Praça Dr. João Mendes, Viaduto Da Paulina, Rua Maria Paula, Viaduto Jacareí, Viaduto 9 de Julho, Av. São Luiz. 
CANDEIAS, J. A. N.; CHRISTOVÃo, D. de A. \& COTILlo Z., L. G. - Isolamento de virus de copos de bares e cafés da cidade de. Rev. Saúde públ., S. Paulo, 2(2):174-179, dez. 1968.

Métodos virológicos - Cada amostra foi inoculada em 5 tubos de cultura de células HeLa e 5 tubos de culturas primárias de rim de macaco Rhesus, usando-se o volume de $0,2 \mathrm{ml}$ de inóculo, por tubo. Incubadas a $37^{\circ} \mathrm{C}$ e observadas, cada dois dias, durante 20 dias, para exame do efeito citopático, eram consideradas negativas as amostras que não ocasionavam qualquer efeito em duas passagens sucessivas.

Cada uma das amostras foi ainda inoculada, por via sub-cutânea, em camundongos recém-nascidos, com menos de 24 horas de idade, na dose de $0,02 \mathrm{ml}$ por animal, em grupos de 5 animais por amostra.

A identificação das amostras isoladas foi feita por provas de neutralização (RoWE et alii ${ }^{10}, 1955$; Hambling, Davies \& MaCRAe $^{6}, 1963$ e APHA $\left.{ }^{2}, 1964\right)$. Os soros padröes homólogos foram fornecidos pela Dra. M. S. Pereira do "Virus Reference Laboratory - Central Public Health Laboratories, Colindale", Londres.

\section{R E S UL T A D O S}

De 7 dos 80 lotes de copos examinados, isto é, de $8,75 \%$, foram isoladas 7 cêpas de vírus, sendo três de adenovírus do tipo 3, duas de vírus ECHO 11, uma de adenovírus do tipo 4 e uma de herpes simples. Os sete lotes positivos correspondem a 7 "bares e cafés" diferentes.

Os resultados obtidos não permitem estabelecimento de nenhuma relação entre época de colheita e maior freqüência de vírus.

\section{I S C U S S O}

A técnica padrão da Associação Americana de Saúde Pública ${ }^{1}$ (1944), destinada à coleta de material de utensílios para a enumeração das bactérias nêles presentes, foi amplamente experimentada antes da sua adoção oficial e tem sido largamente posta à prova, nas condiçōes práticas mais diversas, em diferentes paí. ses. A presente investigação viria demonstrar a possibilidade da sua utilização, na parte que se refere ao método de coleta de material e com a modificação do meio suspensor por nós empregada, na pesquisa de vírus nesse tipo de material. Os resultados obtidos, neste trabalho de campo, parecem confirmar os achados de Keller, Braspenninckx \& KASDAN $^{8}$ (1961) relativos à eficiência do método. Estes autores, utilizando-se de modelos experimentais, demonstraram que, nas condições em que trabalharam, a porcentagem de recuperação do vírus bacteriófago $\mathrm{Tl}$ através do mesmo método de coleta por nós empregado, a partir de superfícies não porosas, se aproximava da precisão obtida na evidenciação de contaminantes bacterianos. Mostraram também que até mesmo se aplicando apenas $12 \mathbf{T C D}_{50}$ de vírus de poliomielite do tipo 1, sôbre uma superfície de 25 centímetros quadrados, ainda era possível revelar a presença do vírus quando a coleta do material era feita 5 minutos após a contaminação.

Por outro lado - e êste é o aspecto de maior importância da presente investigação - o isolamento de vírus, de três espécies diferentes, de $8,75 \%$ dos 80 lotes de copos examinados vem corroborar os achados das duas investigações realizadas anteriormente (ChrISTOVÃO ${ }^{4,5}$, 1947, 1956), confirmando a má situação sanitária dos utensílios de uso comum nos estabelecimentos públicos de alimentação da cidade de São Paulo. Mesmo se admitindo que, de cada lote positivo, apenas um dos copos continha o vírus isolado - hipótese, aliás, que deve ser, no caso presente, a mais provável - ainda, assim, se teria revelado que pelo menos $1,75 \%$ dos copos estava contaminado com vírus, ou seja, 1 de cada 57 copos.

Qual o significado epidemiológico desta elevada proporção de contaminação, é pergunta para a qual não se dispõe atualmente de conhecimentos suficientes para permitir resposta precisa. Para a quase totalidade dos vírus, pelo menos no que 
CANDEIAS, J. A. N.; CHRISTOVAo, D. de A. \& COTILlo Z., L. G. - Isolamento de vírus de copos de bares e cafés da cidade de. Rev. Saúde públ., S. Paulo, z(2):174-179, dez. 1968.

se refere às cêpas selvagens, como também para as bactérias, ainda são desconhecidas as doses mínimas infectantes para o homem. Katz \& PlotKin ${ }^{7}$ (1967) puderam determinar que para a cêpa atenuada Fox de vírus da poliomielite, do tipo III, a dose mínima capaz de infectar infantes prematuros é, pràticamente, igual à dose mínima capaz de infectar as culturas de células. Estes autores, anteriormente (Plotkin \& KARZ ${ }^{\vartheta}, 1965$ ) após revisão das informações disponíveis sôbre a relação entre infectividade para culturas de células e infectividade para o homem e animais, de vírus administrados pela via oral, respiratória ou conjuntival, haviam apresentado, como conclusão, a opinião de que uma dose de vírus infectante para cultura de células é suficiente para infectar o homem, se entrar em contacto com células suscetíveis. A investigação posterior, por êles empreendida, pôde confirmar êste ponto de vista, pelo menos no que diz respeito ao vírus da poliomielite.

Diante dos dados disponíveis, poder-se-ia, assim, julgar os achados da presente investigação como demonstrativos $\mathrm{da}$ existência de risco de infecção na utilização de copos de "bares e cafés" do centro da cidade de São Paulo. $O$ isolamento de adenovírus, vírus ECHO e vírus do herpes simples dêsse material, parece-nos indício claro da possibilidade de isolamento de qualquer outro vírus do grupo respiratório, e, até mesmo, do grupo intestinal. A freqüência relativa do achado de qualquer vírus dêstes dois grandes grupos, deverá depender principalmente da stua incidência particular na população, por ocasião da colheita de material. Será, entretanto, influenciada pela resistência de cada espécie aos fatoôres ambientes.

$\mathrm{O}$ isolamento de vírus, a partir do material examinado, não nos parece de nenhum modo surpreendente, frente aos resultados obtidos nas investigações bacteriológicas anteriores (Christovão ${ }^{4,5}$, 1947, 1956), resultados êstes que, pro- vàvelmente, se repetiriam no caso de se realizar nôvo levantamento daquêle tipo. Com efeito, em 1947 e em 1956, nenhum dos lotes examinados de copos dos "bares e cafés" apresentou número médio de bactérias dentro do limite padrão (100 bactérias) proposto pela Associação Americana de Saúde Pública ${ }^{1}$ (1944). Na realidade, em 1947, apenas $3 \% \mathrm{e}$, em 1956, nenhum dos lotes de utensílios dêste tipo evidenciaram número médio de bactérias igual ou inferior a 1.000. Em 1947, o número médio geral de bactérias dos 448 copos examinados foi de 85.331 e o valor máximo do número médio, por lote, chegou a 720.000. Em 1956, o número médio geral para os 360 copos examinados foi de 92.996 e o valor máximo do número médio, por lote, atingiu . 1.130.000. Além disto, em 1947, foram isolados estreptococos $\beta$-hemolíticos de $45,3 \%$ dos lotes, estafilococos patogênicos de $15,6 \%$, Escherichia coli de $4,7 \%$ e coliformes, em geral, de 64,1\%\%. Em 1956, pelas razóes então apresentadas, não se repetiu a pesquisa de bactérias patogênicas ou potencialmente patogênicas, nem das reveladoras de poluição fecal.

Os resultados das investigações anteriores e da que ora se relata são a conseqüência natural da tọtal ausência da aplicação de qualquer medida efetiva de saneamento dos utensílios de uso comum, nos estabelecimentos públicos de distribuição de alimentos e bebidas da cidade de São Paulo. Estes fatos foram amplamente discutidos nas investigações anteriores (Christovão ${ }^{4,5}, 1947$, 1956), nas quais se apresentou crítica da irracional legislação sanitária que rege a matéria, a qual, para o caso de "copos" exige que sejam "convenientemente lavados em água fervente", medida impossível de ser tomada na quase totalidade dos estabelecimentos, por empregarem métodos manuais de lavagem.

Seria de interêsse que a presente legislação fôsse revista e, em seu lugar, fôssem adotadas medidas eficientes e praticáveis, como as exigidas em códigos sani- 
CANDEIAS, J. A. N.; CHRIStovio, D. de A. \& Cotillo Z., L. G. - Isolamento de virus de copos de bares e cafés da cidade de.. Rev. Saúde públ., S. Paulo, 2(2):174-179, dez. 1968.

tários de estados ou cidades norte-americanas, dois dos quais foram apresentados, como exemplo, em investigação anterior (Christovão 5, 1956), ou como aquelas exigidas em outros países, das quais, em seguida, se apresentam também alguns exemplos.

Assim, na província de Ontário, no Canadá ${ }^{3}$, a lei de saúde pública C.R.O. 332 de 1947, consolidada em 1950, que se refere aos estabelecimentos de distribuição de alimentos, estabelece disposições simples e rígidas, nos artigos de 34 a 43, sôbre "a lavagem e o armazenamento dos utensílios". $O$ artigo 41 exige que êstes não apresentem, em média, mais que 100 bactérias. Os artigos anteriores regulam os métodos de lavagem e desinfecção, exigindo, por exemplo, quando se usam métodos manuais de lavagem, que esta seja realizada em solução de detergente eficiente, mantida a, pelo menos, $43,3^{\circ} \mathrm{C}$, que seja seguida de enxaguadura $e$, em seguida, de "esterilização". Esta será feita, ou através de imersão em água à temperatura mínima de $76,7^{\circ} \mathrm{C}$, durante, pelo menos, 2 minutos, ou de imersão em solução de cloro, de não menos que 100 p.p.m. de cloro disponível e a uma temperatura mínima de $43,3^{\circ} \mathrm{C}$ ou, ainda, pela imersão em solução de composto quaternário de amô. nio na concentração mínima de 200 p.p.m. e à temperatura mínima de $43,3^{\circ} \mathrm{C}$.

$\mathrm{Na}$ União Sul-Africana ${ }^{11}$ (1962) as leis sanitárias da cidade de Johannesburg, na seção 15 do capítulo 8, da Parte IV, exigem que a contagem de bactérias, pelo método padrão, não revele números médios superiores a 100 bactérias por utensilio. Segundo Smith (1), o contrôle de tal exigência é realizado através da Secção de Higiene Promocional do De. partamento de Saúde local, a qual, em 1966, procedeu a 1.678 exames de lotes de utensílios, dos quais apenas 327 acusaram resultados superiores aos permitidos. Ainda segundo Smith (1), o Departamento de Saúde tem agido com sucesso, junto aos fabricantes de equipamento para restaurantes, bares, etc., no sentido de obter a fabricação de esterilizadores de louças, simples e eficientes.

Na URSS, de acôrdo com Liarskii (2), as exigências sanitárias relativas à lavagem de utensílios, em estabelecimentos públicos de alimentação, são regulamentadas por leis sanitárias aprovadas pelo Ministério da Saúde e de execução obrigatória em todos os estabelecimentos desta categoria. Segundo Liarskii (2), a lavagem de utensilios requer a existência de pias de três compartimentos ou de apenas dois, no caso de utensílios de vidro, e o processo de lavagem deve ser o seguinte: a) após a remoção, por meios mecânicos, dos restos de alimentação, os utensílios devem ser lavados, com escôva, em solução de fosfato trissódico a $1 \%$ ou de 0,5 a $2 \%$ de soda cáustica ou outro agente químico aprovado para êste fim, pelo Ministério; b) em seguida, os utensílios são "lavados" em água, à temperatura de $50{ }^{\circ} \mathrm{C}$, adicionada de $10 \mathrm{ml}$ de solução a $1 \%$ de cal clorada para cada litro (o que corresponde a $200-250 \mathrm{mg}$ de cloro ativo), ou de cloramina; c) após esta operação, os utensílios são enxaguados, na terceira pia, em água de temperatura nunca inferior a $70^{\circ} \mathrm{C}$, para o que os utensílios são postos em cestas especiais de tela, as quais são colocadas sôbre grades; d) finalmente, se realiza a secagem em estufas ou sôbre prateleira especial; e) os talheres, de metais inoxidáveis, devem ser lavados da maneira descrita, mas têm, uma vez lavados e co-

(1) Smith, A. H., médico-sanitarista chefe do Departamento de Saúde Pública de Johannesburg, Professor de Administração Sanitária Urbana, Universidade de Witwatersrand: Comunicação pessoal, 1967.

(2) Liarskif, P., chefe do Departamento Sanitário-Epidemiológico Central de Moscou, Ministério da Saúde da URSS: Comunicação pessoal, 1967. 
CANDEIAs, J. A. N.; CHRistovao, D. de A. \& COTILlo Z., L. G. - Isolamento de vírus de copos de bares e cafés da cidade de.. Rev. Sañde pribl., S. Paulo, 2(2):174-179, dez. 1968.

locados em cestas especiais de tela, de ser obrigatòriamente fervidos ou mergulhados em água fervendo durante 1-2 minutos e, depois, submetidos à secagem. Ainda de acôrdo com Liarskii (1), para o contrôle da eficiência das operações de lavagem, os órgãos do Serviço Sanitário-Epidemiológico empregam métodos especiais, aprovados pelo Ministério de Saúde da URSS. Coleta-se e analisa-se a água obtida após a lavagem de utensílios já anteriormente lavados, com a finalidade de verificar a presença ou não de microrganismos do grupo de bacilos intestinais e determinar a quantidade total de bactérias. Nestas amostras d'água, os bacilos intestinais não devem estar presentes.

Medidas eficazes e aplicáveis ao nosso meio deveriam ser estudadas e, após a sua seleção, dever-se-ia cogitar da substituição das atuais disposiçōes sanitárias referentes à matéria — que se têm provado inteiramente inoperantes - pela legislação adequada.

\section{S U M M A R $\mathbf{Y}$}

Seven strains of viruses were isolated from $8.75 \%$ of the 80 lots of drinking glasses, ready for use, in 40 coffee shops and bars in the business district of Sâo Paulo. Three strains were identified as adenovirus type 3 , two as echo type 11 , one as adenovirus type 4 and one as herpesvirus. Each lot consisted of 5 drinking glasses. The positive lots belonged to 7 different coffee shops and bars. These findings confirm the poor sanitary conditions already observed of the common use utensils in the eating and drinking places of the city of São Paulo. These conditions are the result of the total lack of adoption of sanitation measures regarding such material. The existing conditions are the consequence of the inefficient and even infeasible regulations of the present sanitary laws of the State, concerning the matter.

\section{REFERENCTAS BIBLIOGRAFICAS}

1. AMERICAN PUBLIC HEALTH ASSOCIATION. Subcommittee on Food Utensil Sanitation - A proposed method for the control of food utensil sanitation: report. Amer. J. publ. Hlth, 34 (3) :255-258, Mar., 1944.

2. AMERICAN PUBLIC HEALTH ASSOCIATION - Diagnostic procedures for viral and rickettsial diseases. 3rd ed. New York, 1964. p. 396.

3. CANADA. Laws, statutes, etc. - Regulations under the public health act, $C$. R. O. 3s2: eating establishments Ontario, Frank Fogg Publ., 1958.

4. ChristovaO, D. de A. - O problema sanitário dos copos, loucas e talheres dos restaurantes, bases e cafés do centro da cldade de Sáo Paulo, revelado por inquérito bacteriológico. Causas determinantes e sugestōes para a sua solucão. Arq. Fac. Hig. S. Paulo, 1(2):241-264, dez., 1947.

5. - As condiçóes sanitárias dos copos, louças e talheres de restaurantes, bares e cafés do centro da cidade de São Paulo. 29 Inquéríto bacteriológico. Rev. paul. Med., 49(6) :385-408, dez., 1956.

6. HAMBLING, M. H.; DAVIES, P. M. \& MACRAE, A. D. - The typing of enteroviruses in tissue culture by neutralization with composite antiserum pools. J. Hyg., Cambridge, 61(4):479-484, Dec., 1963.

7. KATZ, M. \& PLOTKIN, S. A. - Minimal infective dose of attenuated poliovirus for man. Amer. J, publ. Hith., 5\% (10) :1837-1840, Oct., 1967.

8. KELLER, K.; BRASPENNINOKX, H. \& KASDAN, M. - Detecting viruses on nonporous surface by use of the cotton swab technique. Publ. Hlth. Rep., 76 (5) : 453-458, May, 1961.

9. PLOTKIN, A. \& KATZ, M. - "Mínimal infective doses of viruses for man by the oral route". In: BERG, G. ed. Transmission of viruses by the water route. New York, Wiley \& Sons, 1965. p. 151-166.

10. ROWE, W. P. et alii - Studies of adenoidal-pharingeal-conjunctival (A P C) group of viruses. Amer. J. Hyg., 61(2): 197-218, Mar., 1965.

11. UNIAO SUL-AFRICANA. Laws, statutes, etc. - Public health by by-laws: food handling. Johannesburg, 1962. Part IV, chap. 8, 10 (Reprint).

(1) Nota da página anterior. 